\title{
Hormone- and HER2-receptor assessment in 33,046 breast cancer patients: a nationwide comparison of positivity rates between pathology laboratories in the Netherlands
}

\author{
Carmen van Dooijeweert ${ }^{1} \cdot$ Ivette A. G. Deckers $^{2} \cdot$ Inge O. Baas $^{3} \cdot$ Elsken van der Wall $^{3} \cdot$ Paul J. van Diest $^{1}$ (i)
}

Received: 13 February 2019 / Accepted: 19 February 2019 / Published online: 1 March 2019

(c) The Author(s) 2019

\begin{abstract}
Purpose Patient management of invasive breast cancer (IBC) is to a large extent based on hormone- and HER2-receptor assessment. High-quality, reliable receptor assessment is of key importance as false results may lead to under- or overtreatment of patients. Surveillance of case-mix adjusted positivity rates has been suggested as a tool to identify laboratories with insufficient testing assays, as this covers the whole process of receptor assessment and enables laboratories to benchmark their positivity rates against other laboratories. We studied laboratory-specific variation in hormone- and HER 2 positivity rates of 33,046 breast cancer patients using real-life nationwide data.

Methods All synoptic pathology reports of IBC resection-specimens, obtained between 2013 and 2016, were retrieved from the nationwide Dutch pathology registry (PALGA). Absolute and case-mix adjusted receptor positivity rates were compared to the mean national proportion and presented in funnel plots in separate analyses for estrogen (ER), progesterone (PR) and HER2. Case-mix adjustment was performed by multivariable logistic regression.

Results 33,794 IBC lesions from 33,046 patients of 39 pathology laboratories were included. After case-mix adjustment, mean positivity rates were 87.2\% for ER (range 80.4-94.3), 71.3\% for PR (62.5-77.5\%), and 9.9\% for HER2 (5.5-12.7\%). Overall, 14 (35.9\%), 17 (43.6\%) and 11 (28.2\%) laboratories showed positivity rates outside the $95 \%$ confidence interval for ER, PR and HER2, respectively.

Conclusion This nationwide study shows that absolute variation in hormone- and HER2-receptor positivity rates between Dutch pathology laboratories is limited. Yet, the considerable number of outlying laboratories shows that there is still need for improvement. Continuous monitoring and benchmarking of positivity rates may help to realize this.
\end{abstract}

Keywords Invasive breast cancer $\cdot$ Pathology $\cdot$ Hormone receptor $\cdot$ HER2 $\cdot$ Inter-laboratory variation $\cdot$ PALGA

\section{Introduction}

Patient management of invasive breast cancer (IBC) is to a large extent based on estrogen-(ER), progesterone-(PR) and HER2-receptor assessment as they determine whether

Paul J. van Diest

p.j.vandiest@umcutrecht.nl

1 Department of Pathology, University Medical Center Utrecht, PO Box 85500, 3508 GA Utrecht, The Netherlands

2 Foundation PALGA (the nationwide network and registry of histo- and cytopathology in the Netherlands), Houten, The Netherlands

3 Department of Medical Oncology, University Medical Center, Utrecht, The Netherlands targeted anti-hormonal, anti-HER2 therapy and/or chemotherapy are indicated [1-4]. For early ER- and/or PR-positive breast cancer, the risk of recurrence and mortality is reduced by anti-endocrine therapy, independent of the administration of chemotherapy [5, 6]. In addition, for HER2-positive breast cancer, adjuvant anti-HER2-therapy combined with chemotherapy is considered, regardless of other characteristics like tumor grade [1]. Furthermore, different chemotherapy regimens are considered for HER2-positive breast cancer patients [1].

ER-, PR- or HER2-receptor status of a tumor is established by pathological analysis of tumor tissue by immunohistochemistry (IHC) (ER, PR and HER2) and/or in situ hybridization (ISH) (HER2) [1, 7], which, according to global guidelines, is mandatory for all newly diagnosed primary IBC cases [1, 2, 4, 8-10]. High-quality, reliable 
receptor assessment is of key importance as false-negative results may result in withholding effective treatment, whilst false-positive results could result in overtreatment with costly and ineffective therapy at the same time resulting in unwanted direct and long-term side effects [1,11-16].

The quality of ER-, PR-, and HER2-testing has been extensively studied over the past two decades. Central review of trial cases or cases from local pathology laboratories mainly showed that substantial differences between testing laboratories occurred [3, 17-24], which was confirmed by reversed studies in which samples or tissue microarrays were sent to different laboratories [25-30]. Proficiency testing programs were launched as a promising remedy [31-35], but it has been argued that they render only a temporary and incomplete assessment of testing performance, which does not necessarily reflect reliability of testing over time [7]. For example, crucial steps like tissue fixation and processing are not covered by these tests [36].

Recently, surveillance of positivity rates has been suggested as a tool to identify laboratories with insufficient testing assays and a high yield of false-positive or falsenegative results $[7,14,16,37]$. However, as test accuracy is not the only potential factor in receptor positivity rates, it is important to also take patient and tumor characteristics into account $[14,38]$. Such a study design would enable laboratories and pathologists to compare their receptor positivity rates with other laboratories, while controlling for differences in population characteristics ("case-mix") [38]. This may be crucial to create awareness, as pathologists and their laboratories may feel addressed by their own case-mix adjusted "mirror" data. Previous studies using such a design found significant variation between pathology laboratories in Germany with a range of HER2 positivity rates varying from 7.6 to $31.6 \%$ [7, 14] with significant outliers even after case-mix correction [14]. To the best of our knowledge, such studies have not been performed for ER- and PR-receptor positivity rates.

To create insight and awareness in the Netherlands, we compared ER-, PR- and HER2-receptor positivity rates from daily clinical practice between pathology laboratories using real-life data from synoptic (structured) pathology reports of 33,046 IBC patients from the Dutch nationwide pathology registry (PALGA).

\section{Methods}

\section{Data source and study population}

We extracted data from PALGA, the nationwide network and registry of histo- and cytopathology in the Netherlands, which contains pathology reports from all Dutch pathology laboratories since 1991 [39]. Data from the
PALGA database are pseudonymized by a trusted third party (ZorgTTP, Houten, the Netherlands). As all pathology laboratories were initially anonymized, we obtained further written consent for the additional analysis of interpathologist variation within individual laboratories $(n=7)$. This study was approved by the scientific and privacy committee of PALGA and all data were retrieved and handled in compliance with the General Data Protection Regulation act.

All synoptic pathology reports of patients with IBC resection specimens between January 1, 2013, and December 31, 2016 , in the Netherlands $(n=48,665)$ were extracted. Synchronous IBC was defined as an ipsilateral lesion within six months of the previous IBC resection during the study period. As these lesions were considered paired measurements, we only included the first lesion. Reports of resection specimens without a primary tumor were excluded. Likewise, pathology reports of patients who received neoadjuvant treatment were excluded as tumor receptor status may be converted by neo-adjuvant treatment [40-42] (Fig. 1).

Overall, 40 out of 46 Dutch pathology laboratories reported on breast resection specimens using the synoptic (PALGA) pathology protocol. Of these laboratories, we only included those that synoptically reported $\geq 250$ IBC resection specimens during the study period $(n=39)$. For inter-pathologist variation within individual laboratories, we only analyzed data from pathologists from the consenting laboratories who synoptically reported $\geq 20$ IBC during the study period.

From each pathology report, we extracted patient characteristics (sex, age, type of surgery) and tumor characteristics (tumor size, histologic subtype, histologic grade, ER- and PR-receptor status, and HER2-receptor status). ER- and PRstatus were determined by IHC, whereas HER2-status was determined either by IHC and/or ISH. Lastly, reports of IBC with any missing data (histologic grade, ER, PR- or HER2receptor status) were excluded from further data-analysis (Fig. 1).

\section{Analysis of ER- and PR-receptor status}

Within the synoptic protocol, and according to the Dutch guideline [1], the ER- and PR-receptor status are considered positive when $\geq 10 \%$ of tumor cells show ER- and PRspecific staining by IHC. Overall, both ER- and PR-receptor status were taken into account as a binary variable, either positive $(\geq 10 \%)$ or negative $(<10 \%)$, since the percentage of stained tumor nuclei (not an obligatory item) was not known for $\sim 20 \%$ of cases. When one or both receptors were missing, the status on biopsy was considered the true receptor status $(\sim 7.5 \%)$, as this is common practice in clinical management. 
Fig. 1 Flowchart of included lesions of invasive breast cancer (IBC) to assess variation in receptor (ER, PR, HER2) positivity rates between laboratories

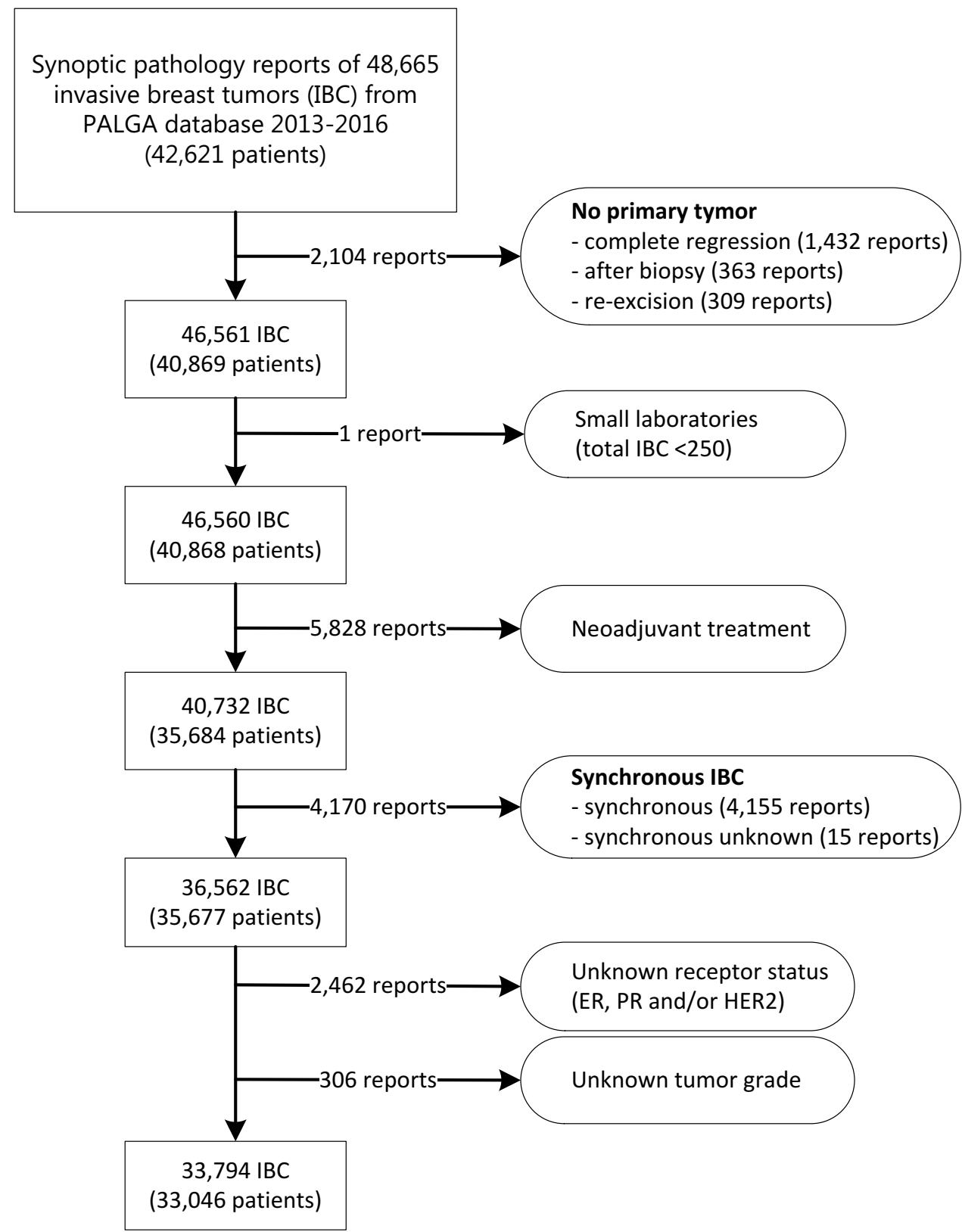

\section{Surrogate intrinsic subtype}

Surrogate intrinsic subtype was established as before by Perou et al. [43] as Luminal A =ER+, PR+/-, HER2-, Luminal $\mathrm{B}=\mathrm{ER}+$, $\mathrm{PR}+/-$, HER 2 + , HER2-driven $=\mathrm{ER}-$, PR,- HER $2+$, Basal-like $=$ ER,- PR,- HER2 - .

\section{Analysis of HER2-receptor status}

HER2-receptor status was taken into account as a binary variable, either positive or negative, regardless of which techniques were used (IHC and/or ISH). In general, and as recommended by the Dutch guideline [1], IHC is performed first, followed by amplification testing in case of a
$2+$ IHC score. As described for ER - and PR, when HER2receptor status was missing on resection specimen, biopsy HER2-receptor status was considered the true receptor status $(5.5 \%)$.

\section{Survey among laboratories}

A survey was sent to all 46 Dutch pathology laboratories to gain insight into their processes and interpretation of receptor assessment in daily clinical practice. The survey included questions on whether receptor status was assessed on biopsy and/or resection specimen, the cutoff percentages used for receptor positivity (ER/PR), the interpretation of IHC scores 
for HER2 $(0,1+, 2+, 3+)$, techniques used for HER2-assessment and the order in which they were executed.

\section{Statistical analysis}

Separate analyses were performed for ER-, PR- and HER2receptor status as outcome measure. Patient and tumor characteristics were summarized and differences between receptorpositive and receptor-negative status (ER, PR and HER2) were tested by means of $\chi^{2}$ test for categorical variables and by a nonparametric Kruskal-Wallis test for continuous variables.

Overall positivity rates per receptor (ER, PR, HER2) were determined and considered the national proportion. Absolute differences in positivity rates between laboratories were presented in funnel plots per receptor, in which the positivereceptor proportions per laboratory were plotted against the number of included IBC reports per laboratory, with the overall national proportion with its $95 \%$ confidence limits as target [44].

For case-mix correction, all available clinicopathological risk factors were selected a priori based on literature [14, $38,45-47]$ and on pathologists' experience. These factors included age, sex, tumor size, type of surgery, histologic subtype, tumor grade and either the combined hormone-receptor status (for HER2-analysis) or HER2-receptor status (for ERand PR-analysis). The combined hormone-receptor status (ER/ PR) was considered positive when either or both the ER- and PR-receptor were reported as positive. Sex was excluded in the final multivariable logistic regression model, as the number of males was too low. However, males did not cluster in specific laboratories. To calculate case-mix adjusted percentages, the observed percentage $(\mathrm{O})$ per laboratory was divided by the expected percentage (E), based on the multivariate logistic regression model, and multiplied by the overall mean positive percentage per receptor $(\mathrm{O} / \mathrm{E} *$ mean $)$. Similar to the crude percentages, case-mix adjusted percentages were presented in funnel plots.

For analysis of the inter-pathologist variation within the laboratories, we merely compared the proportions per receptor (ER, PR and HER2) between pathologists by Fisher exact test (Monte Carlo option).

Survey results were summarized by frequencies and percentages. $P$ values below 0.05 were considered statistically significant. All statistical analyses were performed using IBM SPSS Statistics version 25.

\section{Results}

\section{Characteristics of patients, DCIS lesions and laboratories}

In total, 33,794 unique IBC lesions of 33,046 patients from 39 laboratories were included. Characteristics of all included patients and corresponding invasive breast tumors are listed in Table 1.

Nearly all patients were female $(99.2 \%)$, and the overall mean $( \pm$ standard deviation $(\mathrm{SD}))$ age was $62.2( \pm 12.1)$ years. The majority of patients underwent breast conserving surgery $(63.9 \%)$ for tumors with a mean $( \pm S D)$ of 1.9 $( \pm 1.3) \mathrm{cm}$. HER2 positivity of tumors was associated with higher histologic tumor grade, whereas ER- and PR positivity of tumors was associated with lower tumor grade. HER2positive tumors were less often of lobular subtype and were of larger size than HER2-negative tumors. Furthermore, HER2-positive tumors were less often hormone-receptor positive and vice versa.

The number of synoptically reported IBC lesions per laboratory ranged from 80 to 2224 (median 794). Overall observed positive proportions were $87.2 \%$ for ER, $71.3 \%$ for PR and only $9.9 \%$ for HER2. Regarding the intrinsic breast cancer subtypes, luminal A, luminal B, HER2-driven and basal-like subtypes were observed in $80.5 \%, 6.7 \%, 3.2 \%$ and 9.7\%, respectively (Table 1).

\section{Inter-laboratory variation in ER, PR and HER2 positivity rates}

Positivity rates between laboratories varied most for PR (60.0-78.8\%), followed by ER (77.5-92.7\%) and HER2 (5.3-13.0\%). After case-mix adjustment, the inter-laboratory range slightly decreased for all receptors: PR (62.5-77.5\%), ER (80.4-94.3\%), HER2 (5.5-12.7\%) (Fig. 2). Overall, 17 laboratories (43.6\%) showed positivity rates outside the $95 \%$ CI for PR, followed by 14 laboratories (35.9\%) for ER and 11 laboratories (28.2\%) for HER2 (Fig. 2).

\section{Intra-laboratory variation in ER, PR and HER2 positivity rates}

Sixty-two pathologists from the seven laboratories that participated in the intra-laboratory variation analysis synoptically reported $\geq 20$ IBC during the study period. Per laboratory the number of analyzed pathologists ranged from 3 to 15 (median 9). The number of analyzed IBC reports per pathologist ranged from 20 to 257 (median 81). Overall, positivity ranges for ER, PR and HER2 did not significantly differ between pathologists within individual laboratories, except 
Table 1 Characteristics of the 33,794 included invasive breast cancers from the Dutch national PALGA database 2013-2016

\begin{tabular}{|c|c|c|c|c|c|c|c|}
\hline & $\begin{array}{l}\text { Total } \\
(n=33,794)\end{array}$ & $\begin{array}{l}\text { ER-negative } \\
(n=4337)\end{array}$ & $\begin{array}{l}\text { ER-positive } \\
(n=29,457)\end{array}$ & $\begin{array}{l}\text { PR-negative } \\
(n=9698)\end{array}$ & $\begin{array}{l}\text { PR-positive } \\
(n=24,069)\end{array}$ & $\begin{array}{l}\text { HER2-negative } \\
(n=30,454)\end{array}$ & $\begin{array}{l}\text { HER2-positive } \\
(n=3340)\end{array}$ \\
\hline Age (year)* & $62.2(12.1)$ & $60.9(14.2)$ & $62.4(11.7)$ & $62.9(12.5)$ & $61.9(11.9)$ & $62.5(11.9)$ & $59.6(13.1)$ \\
\hline \multicolumn{8}{|l|}{ Sex, $n(\%)$} \\
\hline Female & $33,540(99.2 \%)$ & $4335(100.0 \%)$ & $29,205(99.1 \%)$ & $9666(99.7 \%)$ & $23,874(99.1 \%)$ & $30,219(99.2 \%)$ & $3321(99.4 \%)$ \\
\hline Male & $254(0.8 \%)$ & $2(0.0 \%)$ & $252(0.9 \%)$ & $32(0.3 \%)$ & $222(0.9 \%)$ & $235(0.8 \%)$ & $19(0.6 \%)$ \\
\hline $\begin{array}{l}\text { Tumor size } \\
(\mathrm{cm})^{*}\end{array}$ & $1.9(1.3)$ & $2.2(1.6)$ & $1.8(1.3)$ & $2.0(1.5)$ & $1.8(1.3)$ & $1.8(1.3)$ & $2.1(1.4)$ \\
\hline \multicolumn{8}{|l|}{$\begin{array}{l}\text { Type of surgery, } \\
n(\%)\end{array}$} \\
\hline Mastectomy & $12,208(36,1 \%)$ & $1902(43.9 \%)$ & $10,306(35.0 \%)$ & $3961(40.8 \%)$ & $8247(34.2 \%)$ & $10,641(34.9 \%)$ & $1567(46.9 \%)$ \\
\hline $\begin{array}{l}\text { Breast con- } \\
\text { serving }\end{array}$ & $21,586(63.9 \%)$ & $2435(56.1 \%)$ & $19,151(65.0 \%)$ & $5737(59.2 \%)$ & $15,849(65.8 \%)$ & $19,813(65.1 \%)$ & $1773(53.1 \%)$ \\
\hline \multicolumn{8}{|l|}{$\begin{array}{l}\text { Histologic sub- } \\
\text { type, n }(\%)\end{array}$} \\
\hline Ductal & $28,549(84.5 \%)$ & $3763(86.8 \%)$ & $24,786(84.1 \%)$ & $8137(83.9 \%)$ & $20,412(84.7 \%)$ & $25,416(83.5 \%)$ & $3133(93.8 \%)$ \\
\hline Lobular & $4429(13.1 \%)$ & $95(2.1 \%)$ & $4334(14.7 \%)$ & $1,012(10.4 \%)$ & $3417(14.2 \%)$ & $4291(14.1 \%)$ & $138(4.1 \%)$ \\
\hline Other & $816(2.4 \%)$ & $479(11.0 \%)$ & $337(1.1 \%)$ & $549(5.7 \%)$ & $267(1.1 \%)$ & $747(2.5 \%)$ & $69(2.1 \%)$ \\
\hline \multicolumn{8}{|l|}{$\begin{array}{l}\text { Histologic } \\
\quad \text { grade, } n(\%)\end{array}$} \\
\hline Grade 1 & $9494(28.1 \%)$ & $130(3.0 \%)$ & $9364(31.8 \%)$ & $1487(15.3 \%)$ & $8007(33.2 \%)$ & $9283(30.5 \%)$ & $211(6.3 \%)$ \\
\hline Grade 2 & $16,103(47.1 \%)$ & $964(22.2 \%)$ & $15,139(51.4 \%)$ & $3696(38.1 \%)$ & $12,407(51.5 \%)$ & $14,767(48.5 \%)$ & $1336(40.0 \%)$ \\
\hline Grade 3 & $8197(24.3 \%)$ & $3243(74.8 \%)$ & $4954(16.8 \%)$ & $4515(46.6 \%)$ & $3682(15.3 \%)$ & $6404(21.0 \%)$ & $1793(53.7 \%)$ \\
\hline \multicolumn{8}{|l|}{$\begin{array}{l}\text { Combined ER/ } \\
\text { PR status, } n \\
(\%)\end{array}$} \\
\hline Negative & $4216(12.5 \%)$ & - & - & - & - & $3179(10.4 \%)$ & $1037(31.0 \%)$ \\
\hline Positive & $29,578(87.5 \%)$ & - & - & - & - & $27,275(89.6 \%)$ & $2303(69.0 \%)$ \\
\hline \multicolumn{8}{|l|}{$\begin{array}{l}\text { HER2-receptor } \\
\text { status, } n(\%)\end{array}$} \\
\hline Negative & $30,454(90.1 \%)$ & $3265(75.3 \%)$ & $27,189(92.3 \%)$ & $7,866(81.1 \%)$ & $22,588(93.7 \%)$ & - & - \\
\hline Positive & $3340(9.9 \%)$ & $1072(24.7 \%)$ & $2268(7.7 \%)$ & $1832(18.9 \%)$ & $1508(6.3 \%)$ & - & - \\
\hline \multicolumn{8}{|l|}{$\begin{array}{l}\text { Intrinsic sub- } \\
\text { types** }\end{array}$} \\
\hline Luminal A & $27,189(80.5 \%)$ & - & - & - & - & - & - \\
\hline Luminal B & $2.268(6.7 \%)$ & - & - & - & - & - & - \\
\hline HER2-driven & $1.072(3.2 \%)$ & - & - & - & - & - & - \\
\hline Basal-like & $3.265(9.7 \%)$ & - & - & - & - & - & - \\
\hline
\end{tabular}

* Mean (SD)

** Luminal A = ER+, PR+/-, HER2-, Luminal B = ER+, PR+/-, HER 2+, HER2-driven = ER-, PR-, HER2+, Basal-like = ER-, PR-, HER 2-

*** $P$ values for all variables (positive versus negative receptor status) $<0.0005$, except for males and HER2 $(P=0.198)$

for ER positivity rates of the three pathologists from one laboratory (laboratory 10, positivity rates $90.1 / 98.8 / 92.9 \%$, $P=0.032$, data not shown).

\section{Results of survey}

Thirteen of the 46 Dutch pathology laboratories (28.3\%) responded to our online survey, of which six were academic laboratories (Table 2). All responding laboratories participated in mandatory external audits (SKML, NordiQC and/or UK-Neqas) and all IHC stainings were executed mechanically. The vast majority of responding laboratories (92.3\%) currently performs receptor assessment on biopsy, which is usually only repeated on resection specimen in case of a negative staining. In accordance with the Dutch national guideline (1), all laboratories, except for one, use $10 \%$ as a cutoff for ER and PR positivity. The laboratory that uses a different cutoff percentage, i.e., $1 \%$, was not included in our 

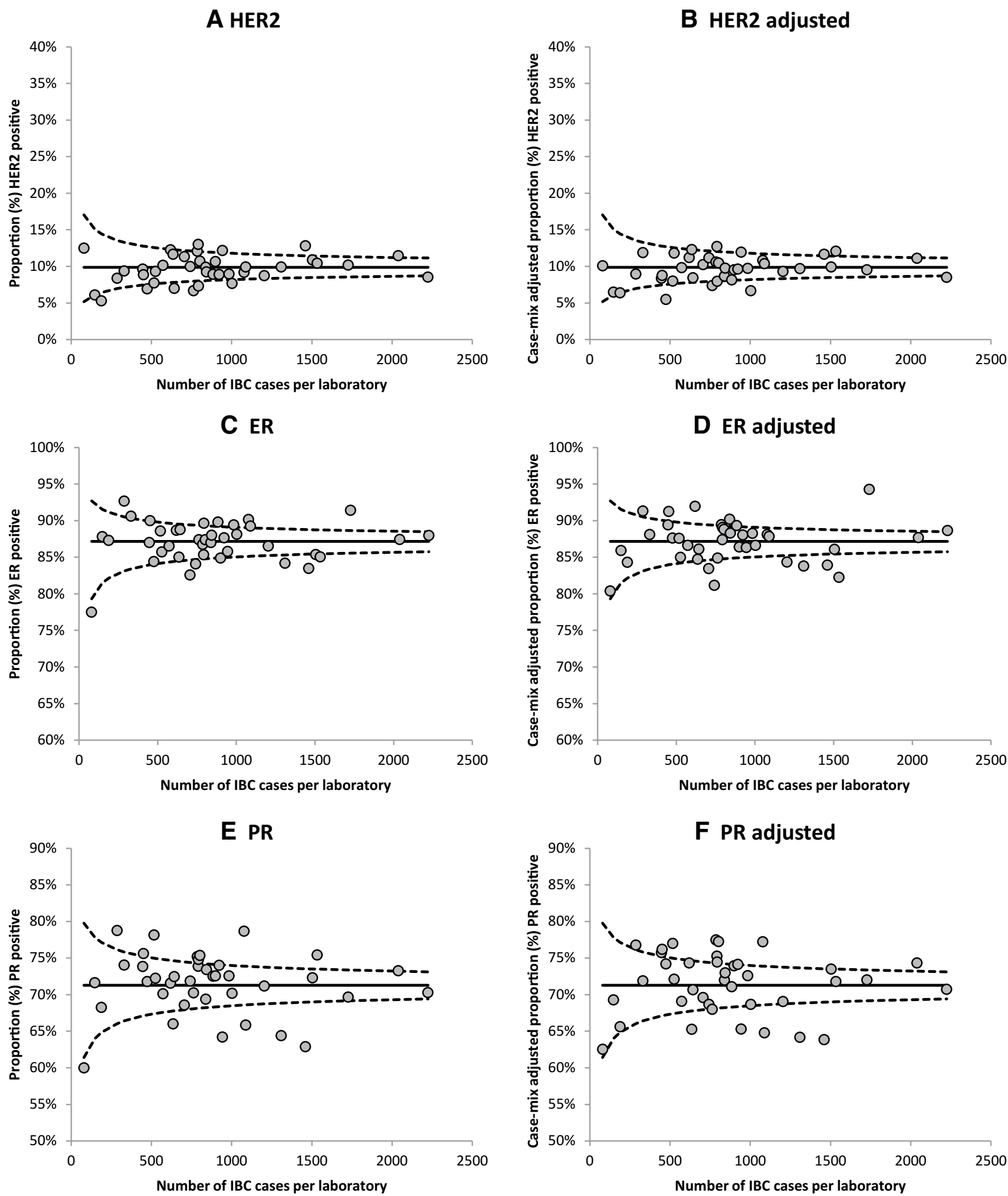

Fig. 2 Funnel plots showing the observed $(\mathbf{a}, \mathbf{c}, \mathbf{e})$ and case-mix adjusted positivity rates $(\mathbf{b}, \mathbf{d}, \mathbf{f})$ per laboratory (dots) relative to the mean national proportion and its 95\% confidence intervals for, for HER2 (a, b), estrogen (ER) (c, d) and progesterone (PR) (e, f) (2013-2016) 
Table 2 Responses of 13 laboratories to our survey on receptor assessment of invasive breast cancer

\begin{tabular}{|c|c|c|}
\hline$n(\%)$ & & \\
\hline Total $(n=13)(\%)$ & Academic $(n=6)(\%)$ & $\begin{array}{l}\text { Non- } \\
\text { academic } \\
(n=7)(\%)\end{array}$ \\
\hline
\end{tabular}

\begin{tabular}{|c|c|c|c|}
\hline \multicolumn{4}{|l|}{ Testing on biopsy or resection specimen? } \\
\hline Biopsy $^{\mathrm{a}}$ & $12(92.3)$ & $6(100.0)$ & $6(85.7)$ \\
\hline Resection specimen $^{\mathrm{b}}$ & $1(7.7)$ & $0(0.0)$ & $1(14.3)$ \\
\hline Both & $3(23.1)$ & $3(50.0)$ & $0(0.0)$ \\
\hline \multicolumn{4}{|l|}{ Used cutoff for ER- and PR-receptor positivity? (\%) } \\
\hline$\geq 1$ & $1(7.7)$ & $1(16.7)$ & $0(0.0)$ \\
\hline$\geq 10$ & $9(69.2)$ & $4(66.7)$ & $5(71.4)$ \\
\hline$\geq 11$ & $3(23.1)$ & $1(16.7)$ & $2(28.6)$ \\
\hline \multicolumn{4}{|l|}{ Used techniques for HER2-receptor assessment ${ }^{\mathrm{c}}$} \\
\hline Immunohistochemistry (IHC) & $13(100.0)$ & $6(100.0)$ & $7(100.0)$ \\
\hline Fluorescence in situ hybridization (FISH) & $7(53.8)$ & $4(66.7)$ & $3(42.9)$ \\
\hline Silver in situ hybridization (SISH) & $5(38.5)$ & $3(50.0)$ & $2(28.6)$ \\
\hline Chromogenic in situ hybridization (CISH) & $1(7.7)$ & $0(0.0)$ & $1(14.3)$ \\
\hline Multiplex ligation-dependent probe amplification & $1(7.7)$ & $1(16.7)$ & $0(0.0)$ \\
\hline Next generation sequencing & $1(7.7)$ & $1(16.7)$ & $0(0.0)$ \\
\hline \multicolumn{4}{|l|}{ HER2-receptor: order of testing techniques } \\
\hline IHC followed by amplification testing & $10(76.9)$ & $4(66.7)$ & $6(85.7)$ \\
\hline FISH followed by IHC when indicated & $3(23.1)$ & $2(33.3)$ & $1(14.3)$ \\
\hline \multicolumn{4}{|l|}{ Primary IHC HER2-test $(n=10)$ scores } \\
\hline \multicolumn{4}{|l|}{ Score 0} \\
\hline Reported as negative & $10(100.0)$ & $4(100.0)$ & $6(100.0)$ \\
\hline \multicolumn{4}{|l|}{ Score $1+$} \\
\hline Reported as negative & $9(90.0)$ & $4(100.0)$ & $6(100.0)$ \\
\hline Additional amplification test & $1(10.0)$ & $1(25.0)$ & $0(0.0)$ \\
\hline \multicolumn{4}{|l|}{ Score $2+$} \\
\hline Additional amplification test & $10(100.0)$ & $4(100.0)$ & $6(100.0)$ \\
\hline \multicolumn{4}{|l|}{ Score $3+$} \\
\hline Reported as positive & $8(80.0)$ & $3(75.0)$ & $5(83.3)$ \\
\hline Additional amplification test & $2(20.0)$ & $1(25.0)$ & $1(16.7)$ \\
\hline
\end{tabular}

${ }^{a}$ Most laboratories repeat receptor assessment on resection specimen in case of a negative receptor status on biopsy

${ }^{\mathrm{b}}$ Receptor assessment on biopsy only when requested by clinician

${ }^{c} \geq 1$ answer possible

dataset, as they did not synoptically report on breast cancer during the study period. For HER2 testing, $23.1 \%$ of the responding laboratories uses an amplification test (FISH), possibly followed by IHC, as primary test. In addition, one academic laboratory performed amplification testing after any plus-score (i.e., $1+, 2+, 3+$ ).

\section{Discussion}

We studied inter-laboratory variation in ER, PR, and HER2 positivity rates in a nationwide cohort of 33,046 invasive breast cancer patients, using real-life data from synoptic pathology reports of the Dutch nationwide pathology registry (PALGA). The results of this study show that absolute differences of ER, PR and HER2 positivity rates between laboratories were reassuringly limited. However, the number of outlying laboratories after case-mix adjustment for ER (14/39), PR (17/39) and HER2 (11/39) clearly shows that there is still room for improvement.

Overall positivity rates were $87.2 \%$ for ER, $71.3 \%$ for PR and $9.9 \%$ for HER2, which, for ER and PR, is in line with previous studies [48-50], whereas for HER2 this is somewhat lower than the percentages of $15 \%-25 \%$ that are often referred to $[7,14,16,26,51-53]$. Although we only included synoptic pathology reports, there is no reason to assume 
that our synoptic dataset may have been selective, since data from the Dutch Breast Cancer Audit (NBCA), which also holds data from narrative pathology reports, show similar receptor positivity rates [49]. Moreover, over $80 \%$ of (pre) malignant breast lesions are currently reported via the synoptic PALGA protocol by Dutch pathologists [54], which results in an increased overall completeness of reports [55] and it enables easy and error-free data extraction. This study stresses the potential of using a population-based registry as it provides information on the actual situation in daily clinical practice, which may differ from data derived from clinical trials, from smaller cohorts or even from neighboring countries.

It could be argued that positivity rates in this study may have been biased for several reasons. First, in case of a missing receptor status on resection specimen, the receptor status of the biopsy, when known from the resection pathology report, was included in the analysis. As, however, discrepancies of receptor status between biopsy and resection specimen are uncommon and, according to literature, results from the core biopsy can be used with confidence [56-60], there is no reason to assume that this has influenced our positivity rates. Secondly, we excluded pathology reports with a missing ER-, PR- or HER2-receptor status $(n=2462)$. For the majority of these missing values ( 70-75\%), the tumor receptor status was reported as "in progress". As IHC staining usually takes overnight, the definitive receptor status may have been added as a narrative addendum to the pathology report afterward, yet not to the synoptic PALGA protocol, and therefore, it is unknown in this dataset. However, it is unlikely that this happens more often to receptor-positive than to receptor-negative tumors. For the remaining 735 reports with missing values, the reason remained unknown.

Overall, receptor positivity rates of individual laboratories were compared to the mean national positivity rates, with and without correction for case-mix. Case-mix adjustment only slightly narrowed the range of positivity rates between laboratories, which indicates that there is either little variation in case-mix per laboratory in the Netherlands, or there is little effect of the included case-mix variables. Either way, case-mix does not explain the inter-laboratory differences in this study. In addition, as laboratories with both few and many reports showed positivity rates outside the 95\% CI (Fig. 2), laboratory sample size also does not explain the inter-laboratory variation that was found in this study. Furthermore, variation between individual pathologists within laboratories was minimal, which suggests that factors other than pathologists' interpretation of the fixed and immunohistochemically stained tissue slides may explain the inter-laboratory differences in receptor positivity rates. One could for example think of different ways of tissue fixation or the use of different antibodies between laboratories.
Despite the low response rate of our survey (13/46 laboratories), it did show that, in spite of a clear national guideline, one of the 13 responding laboratories uses a different positivity threshold for ER and PR, which is undesirable as this would result in different therapy advice in our country, even if two laboratories would estimate the same percentage of ER or PR stained nuclei. As all laboratories in this study are anonymous, the results of our survey could not be linked to the laboratories in the dataset. Therefore, it remains unknown whether the use of different positivity thresholds ( $1 \%$ vs. $10 \%)$ may (partially) cause the found inter-laboratory variation. However, we do know that only a fairly small proportion of patients shows "arguable" staining percentages between 1 and 10\%. For both ER and PR, the percentage of staining was known in approximately $80 \%$ of reports and of those reports, $1.3 \%$ showed ER percentages between 1 and $10 \%$, whereas this was the case for $7.5 \%$ for PR. Therefore, the overall influence of (possible) different cutoff percentages is probably be limited.

A nationwide multidisciplinary breast cancer audit (NBCA) has already been implemented in breast cancer care in the Netherlands [49], yet currently there is only one pathology indicator, i.e., whether the PALGA protocol is used for reporting on (pre)malignant breast lesions [61]. We believe that it is important to use this synoptic PALGA protocol to monitor and benchmark the major pathology breast cancer biomarkers, namely ER, PR, HER2 and histologic grade, as these are crucial in decision making in current clinical practice [1]. Although molecular or genetic measures of prognosis may become increasingly important in IBC risk stratification in the near future, the only three mandatory breast cancer biomarkers are still ER-, PR- and HER2receptor status, despite the massive investment of time and money into development of new biomarkers [4]. What is more, Groenendijk et al. [62] showed that the distribution of genomic risk is mainly influenced by histologic grade and ER- and HER2-status, which shows that these classic biomarkers remain very relevant. Given their prominent role in clinical practice, it seems worthwhile to invest in better and more uniform assessment of these classic biomarkers.

We believe that creating insight and awareness in variation of clinically relevant biomarkers through annual individual pathology "mirror" reports is an important step toward improvement in breast cancer care. Monitoring the receptor positivity rates may help to identify laboratories with a high number of false-positive or false-negative results $[7,14,16,37,38]$ that are not picked up by the external audits, since crucial steps like tissue fixation and processing are not covered by these tests [36]. Furthermore, pathologists and their laboratories may feel best addressed by their own, case-mix adjusted, "mirror" data visualized against other national laboratories. Indeed, in a previous nationwide breast cancer audit, a HER2-outlier hospital critically 
evaluated their laboratory process and found that they used a different approach to HER2 positivity [49].

In conclusion, this nationwide study shows that there is limited absolute variation in ER-, PR- and HER2-receptor positivity rates between Dutch pathology laboratories in daily clinical practice. Yet, the considerable number of outlying laboratories shows that there is still room for improvement. Continuous monitoring and benchmarking of positivity rates may help to realize this and has been implemented in the Netherlands.

Acknowledgements The authors thank all pathology laboratories that participated in this study.

Funding This study was funded by the Quality Foundation of the Dutch Association of Medical Specialists (SKMS). The funding source had no role in the design and conduct of this study, nor did it have a role in the review or approval of the manuscript and the decision to submit the manuscript for publication.

\section{Compliance with ethical standards}

Conflict of interest Authors CD (1), ID (2), IB (3) and EW (4) declare no conflict of interest. Author PD (5) received the SKMS research grant.

Ethical approval All procedures performed in studies involving human participants were in accordance with the ethical standards of the institutional and/or national research committee and with the 1964 Helsinki Declaration and its later amendments or comparable ethical standards. This study was approved by the scientific and privacy committee of PALGA (the nationwide registry of histo- and cytopathology in the Netherlands). As this study was performed retrospectively on anonymized data and did not involve subjecting patients to anything, consent from the ethics committee was not required according to the Dutch law. All data were retrieved and handled in compliance with the General Data Protection Regulation (GDPR).

Informed consent All data from the PALGA database are pseudonymized by a trusted third party (ZorgTTP, Houten, the Netherlands). We only ever received fully anonymized data. Data of patients who object against the scientific use of their (anonymized) data are not included in the PALGA database. Therefore, waiver of informed consent is applicable.

Open Access This article is distributed under the terms of the Creative Commons Attribution 4.0 International License (http://creativeco mmons.org/licenses/by/4.0/), which permits unrestricted use, distribution, and reproduction in any medium, provided you give appropriate credit to the original author(s) and the source, provide a link to the Creative Commons license, and indicate if changes were made.

\section{References}

1. The Netherlands Comprehensive Cancer Organization (IKNL). Breast Cancer Guideline 2017 [updated 2012-07-02]. Available from: https://www.oncoline.nl/borstkanker. Accessed 17 Jan 2019
2. Coates AS, Winer EP, Goldhirsch A et al (2015) Tailoring therapies-improving the management of early breast cancer: St Gallen international expert consensus on the primary therapy of early breast cancer 2015. Ann Oncol 26(8):1533-1546

3. McCullough AE, Dell'orto P, Reinholz MM et al (2014) Central pathology laboratory review of HER2 and ER in early breast cancer: an ALTTO trial [BIG 2-06/NCCTG N063D (Alliance)] ring study. Breast Cancer Res Treat 143(3):485-492

4. Duffy MJ, Harbeck N, Nap M et al (2017) Clinical use of biomarkers in breast cancer: updated guidelines from the European Group on tumor markers (EGTM). Eur J Cancer 75:284-298

5. Early Breast Cancer Trialists' Collaborative Group (EBCTCG) (2005) Effects of chemotherapy and hormonal therapy for early breast cancer on recurrence and 15-year survival: an overview of the randomised trials. Lancet 365(9472):1687-1717

6. Davies C, Godwin J, Gray R et al (2011) Relevance of breast cancer hormone receptors and other factors to the efficacy of adjuvant tamoxifen: patient-level meta-analysis of randomised trials. Lancet 378(9793):771-784

7. Choritz H, Busche G, Kreipe H (2011) Quality assessment of HER 2 testing by monitoring of positivity rates. Virchows Arch 459(3):283-289

8. Burstein HJ, Temin S, Anderson H et al (2014) Adjuvant endocrine therapy for women with hormone receptor-positive breast cancer: American society of clinical oncology clinical practice guideline focused update. J Clin Oncol 32(21):2255-2269

9. Senkus E, Kyriakides S, Ohno S et al (2015) on behalf of the ESMO guidelines committee; primary breast cancer: ESMO clinical practice guidelines for diagnosis, treatment and followup. Ann Oncol 26(suppl_5):v8-v30

10. Hammond MEH, Hayes DF, Dowsett M et al (2010) American Society of Clinical Oncology/College of American Pathologists Guideline recommendations for immunohistochemical testing of estrogen and progesterone receptors in breast cancer. J Clin Oncol 28(16):2784-2795

11. Bowles EJA, Wellman R, Feigelson HS et al (2012) Risk of heart failure in breast cancer patients after anthracycline and trastuzumab treatment: a retrospective cohort study. J Natl Cancer Inst 104(17):1293-1305

12. Perez EA, Suman VJ, Davidson NE et al (2008) Cardiac Safety analysis of doxorubicin and cyclophosphamide followed by paclitaxel with or without trastuzumab in the north central cancer treatment group N9831 adjuvant breast cancer trial. J Clin Oncol 26(8):1231-1238

13. Romond EH, Jeong JH, Rastogi P et al (2012) Seven-year follow-up assessment of cardiac function in NSABP B-31, a randomized trial comparing doxorubicin and cyclophosphamide followed by paclitaxel (ACP) with ACP plus trastuzumab as adjuvant therapy for patients with node-positive, human epidermal growth factor receptor 2-positive breast cancer. J Clin Oncol 30(31):3792-3799

14. Rüschoff J, Lebeau A, Kreipe H et al (2016) Assessing HER2 testing quality in breast cancer: variables that influence HER2 positivity rate from a large, multicenter, observational study in Germany. Mod Pathol 30:217

15. Russell SD, Blackwell KL, Lawrence J et al (2010) Independent adjudication of symptomatic heart failure with the use of doxorubicin and cyclophosphamide followed by trastuzumab adjuvant therapy: a combined review of cardiac data from the national surgical adjuvant breast and bowel project B-31 and the north central cancer treatment group N9831 clinical trials. J Clin Oncol 28(21):3416-3421

16. Wolff AC, Hammond ME, Hicks DG et al (2013) Recommendations for human epidermal growth factor receptor 2 testing in breast cancer: American Society of Clinical Oncology/College of 
American Pathologists clinical practice guideline update. J Clin Oncol 31(31):3997-4013

17. Cuadros M, Cano C, Lopez FJ et al (2011) HER2 status in breast cancer: experience of a Spanish National reference centre. Clin Transl Oncol 13(5):335-340

18. Denkert C, Huober J, Loibl S et al (2013) HER2 and ESR1 mRNA expression levels and response to neoadjuvant trastuzumab plus chemotherapy in patients with primary breast cancer. Breast Cancer Res 15(1):R11

19. Orlando L, Viale G, Bria E et al (2016) Discordance in pathology report after central pathology review: implications for breast cancer adjuvant treatment. Breast 30:151-155

20. Paik S, Bryant J, Tan-Chiu E et al (2002) Real-world performance of HER2 testing - national surgical adjuvant breast and bowel project experience. J Natl Cancer Inst 94(11):852-854

21. Perez EA, Suman VJ, Davidson NE et al (2006) HER2 testing by local, central, and reference laboratories in specimens from the North Central Cancer treatment group N9831 intergroup adjuvant trial. J Clin Oncol 24(19):3032-3038

22. Roche PC, Suman VJ, Jenkins RB et al (2002) Concordance between local and central laboratory HER 2 testing in the breast intergroup trial N9831. J Natl Cancer Inst 94(11):855-857

23. Rosa M, Khazai L (2017) Comparison of HER2 testing among laboratories: our experience with review cases retested at Moffitt Cancer Center in a two-year period. Breast J 24(2):139-147

24. Viale G, Regan MM, Maiorano E et al (2007) Prognostic and predictive value of centrally reviewed expression of estrogen and progesterone receptors in a randomized trial comparing letrozole and tamoxifen adjuvant therapy for postmenopausal early breast cancer: BIG 1-98. J Clin Oncol 25(25):3846-3852

25. Bianchi S, Caini S, Paglierani M et al (2015) Accuracy and reproducibility of HER2 Status in breast cancer using immunohistochemistry: a quality control study in tuscany evaluating the impact of updated 2013 ASCO/CAP recommendations. Pathol Oncol Res 21(2):477-485

26. Dowsett M, Hanna WM, Kockx M et al (2007) Standardization of HER2 testing: results of an international proficiency-testing ring study. Mod Pathol 20:584

27. Layfield LJ, Goldstein N, Perkinson KR, Proia AD (2003) Interlaboratory variation in results from immunohistochemical assessment of estrogen receptor status. Breast J 9(3):257-259

28. Parker RL, Huntsman DG, Lesack DW et al (2002) Assessment of interlaboratory variation in the immunohistochemical determination of estrogen receptor status using a breast cancer tissue microarray. Am J Clin Pathol 117(5):723-728

29. Regitnig P, Reiner A, Dinges HP et al (2002) Quality assurance for detection of estrogen and progesterone receptors by immunohistochemistry in Austrian pathology laboratories. Virchows Arch 441(4):328-334

30. Rhodes A, Jasani B, Balaton AJ et al (2001) Study of interlaboratory reliability and reproducibility of estrogen and progesterone receptor assays in Europe. Documentation of poor reliability and identification of insufficient microwave antigen retrieval time as a major contributory element of unreliable assays. Am J Clin Pathol 115(1):44-58

31. Fitzgibbons PL, Murphy DA, Dorfman DM et al (2006) Interlaboratory comparison of immunohistochemical testing for HER2: results of the 2004 and 2005 College of American Pathologists HER2 immunohistochemistry tissue microarray survey. Arch Pathol Lab Med 130(10):1440-1445

32. Rhodes A, Jasani B, Anderson E et al (2002) Evaluation of HER-2/neu immunohistochemical assay sensitivity and scoring on formalin-fixed and paraffin-processed cell lines and breast tumors: a comparative study involving results from laboratories in 21 countries. Am J Clin Pathol 118(3):408-417
33. Rudiger T, Hofler H, Kreipe $\mathrm{HH}$ et al (2002) Quality assurance in immunohistochemistry: results of an interlaboratory trial involving 172 pathologists. Am J Surg Pathol 26(7):873-882

34. von Wasielewski R, Mengel M, Wiese B et al (2002) Tissue array technology for testing interlaboratory and interobserver reproducibility of immunohistochemical estrogen receptor analysis in a large multicenter trial. Am J Clin Pathol 118(5):675-682

35. von Wasielewski R, Hasselmann S, Ruschoff J et al (2008) Proficiency testing of immunohistochemical biomarker assays in breast cancer. Virchows Arch 453(6):537-543

36. Tong LC, Nelson N, Tsourigiannis J, Mulligan AM (2011) The effect of prolonged fixation on the immunohistochemical evaluation of estrogen receptor, progesterone receptor, and HER2 expression in invasive breast cancer: a prospective study. Am J Surg Pathol 35(4):545-552

37. Rakha EA, Pinder SE, Bartlett JM et al (2015) Updated UK Recommendations for HER2 assessment in breast cancer. J Clin Pathol 68(2):93-99

38. Lin CY, Carneal EE, Lichtensztajn DY et al Regional variability in percentage of breast cancers reported as positive for HER 2 in California: implications of patient demographics on laboratory benchmarks. Am J Clin Pathol 148(3):199-207

39. Casparie M, Tiebosch ATMG, Burger G et al (2007) Pathology databanking and biobanking in The Netherlands, a Central Role for PALGA, the nationwide histopathology and cytopathology data network and archive. Cell Oncol 29(1):19-24

40. Xian Z, Quinones AK, Tozbikian G, Zynger DL (2017) Breast cancer biomarkers before and after neoadjuvant chemotherapy: does repeat testing impact therapeutic management? Hum Pathol 62:215-221

41. Yang YF, Liao YY, Li LQ et al (2013) Changes in ER, PR and HER2 receptors status after neoadjuvant chemotherapy in breast cancer. Pathol Res Pract 209(12):797-802

42. Yang L, Zhong X, Pu T et al (2018) Clinical significance and prognostic value of receptor conversion in hormone receptor positive breast cancers after neoadjuvant chemotherapy. World J Surg Oncol 16(1):51

43. Perou CM, Sorlie T, Eisen MB et al (2000) Molecular portraits of human breast tumours. Nature 406(6797):747-752

44. Spiegelhalter DJ. Funnel plots for comparing institutional performance. Stat Med 24(8):1185-1202

45. Huang HJ, Neven P, Drijkoningen M et al (2005) Association between tumour characteristics and HER-2/neu by immunohistochemistry in 1362 women with primary operable breast cancer. J Clin Pathol 58(6):611-616

46. Sullivan PS, Apple SK (2009) Should histologic type be taken into account when considering neoadjuvant chemotherapy in breast carcinoma? Breast J 15(2):146-154

47. Tubiana-Hulin M, Stevens D, Lasry S et al (2006) Response to neoadjuvant chemotherapy in lobular and ductal breast carcinomas: a retrospective study on 860 patients from one institution. Ann Oncol 17(8):1228-1233

48. Parise CA, Caggiano V (2014) Breast cancer survival defined by the ER/PR/HER2 subtypes and a surrogate classification according to tumor grade and immunohistochemical biomarkers. J Cancer Epidemiol 2014:469251

49. van Bommel AC, Spronk PE, Peeters MTV et al (2017) Clinical auditing as an instrument for quality improvement in breast cancer care in the Netherlands: the national NABON breast cancer audit. J Surg Oncol 115(3):243-249

50. van Deurzen CH (2016) Predictors of surgical margin following breast-conserving surgery: a large population-based cohort study. Ann Surg Oncol 23(Suppl 5):627-633

51. Hynes NE, Stern DF (1994) The biology of erbB-2/neu/ HER-2 and its role in cancer. Biochim Biophys Acta 1198(2-3):165-184 
52. Owens MA, Horten BC, Da Silva MM (2004) HER2 amplification ratios by fluorescence in situ hybridization and correlation with immunohistochemistry in a cohort of 6556 breast cancer tissues. Clin Breast Cancer 5(1):63-69

53. Ross JS (2009) Breast cancer biomarkers and HER2 testing after 10 years of anti-HER2 therapy. Dru News Perspect 22(2):93-106

54. Foundation PALGA (2017) Annual report 2017. https://www. palga.nl/assets/uploads/Jaarverslag/Jaarverslag_2017_websitever sie.pdf. Accessed 17 Jan 2019

55. Sluijter CE, van Lonkhuijzen LR, van Slooten HJ et al (2016) The effects of implementing synoptic pathology reporting in cancer diagnosis: a systematic review. Virchows Arch 468(6):639-649

56. Arnedos M, Nerurkar A, Osin P et al (2009) Discordance between core needle biopsy (CNB) and excisional biopsy (EB) for estrogen receptor (ER), progesterone receptor $(\mathrm{PgR})$ and HER2 status in early breast cancer (EBC). Ann Oncol 20(12):1948-1952

57. Clark BZ, Onisko A, Assylbekova B et al (2018) Breast cancer global tumor biomarkers: a quality assurance study of intratumoral heterogeneity. Mod Pathol. https://doi.org/10.1038/s4137 9-018-0153-0

58. Chen X, Yuan Y, Gu Z, Shen K (2012) Accuracy of estrogen receptor, progesterone receptor, and HER2 status between core needle and open excision biopsy in breast cancer: a meta-analysis. Breast Cancer Res Treat 134(3):957-967

59. Dekker TJ, Smit VT, Hooijer GK et al (2013) Reliability of core needle biopsy for determining ER and HER2 status in breast cancer. Ann Oncol 24(4):931-937

60. Tsuda H, Kurosumi M, Umemura S et al (2010) HER2 testing on core needle biopsy specimens from primary breast cancers: interobserver reproducibility and concordance with surgically resected specimens. BMC Cancer 10:534

61. Dutch Institute for Clinical Auditing (DICA)/ Netherlands Comprehensive Cancer Organisation/ NABON Breast Cancer Audit (NBCA) (2018) Factsheet Indicators NABON Breast Cancer Audit (NBCA) 2018, version 2018.3

62. Groenendijk FH, Jager A, Cardoso F, van Deurzen CHM (2018) A nationwide registry-based cohort study of the MammaPrint genomic risk classifier in invasive breast cancer. Breast $38: 125-131$

Publisher's Note Springer Nature remains neutral with regard to jurisdictional claims in published maps and institutional affiliations. 